Revue

Revue de l'histoire des religions

de Ihistoire des religions

Marie-Hélène BLANCHET, Frédéric GABRIEL (éd.), Réduire le schisme? Ecclésiologies et politiques de l'Union entre Orient et Occident (XIII ${ }^{e}-\mathrm{XVIII}{ }^{e}$ siècles)

Paris, Collège de France - CNRS/Centre de recherche d'histoire et civilisation de Byzance (« Monographies », 39), 2013

\title{
Camille Rouxpetel
}

\section{OpenEdition}

\section{Journals}

Édition électronique

URL : http://journals.openedition.org/rhr/8436

DOI : 10.4000/rhr.8436

ISSN : 2105-2573

\section{Éditeur}

Armand Colin

\section{Édition imprimée}

Date de publication : 1 septembre 2015

Pagination : 452-454

ISBN : 978-2-200-92993-0

ISSN : 0035-1423

\section{Référence électronique}

Camille Rouxpetel, « Marie-Hélène blanchet, Frédéric gabriel (éd.), Réduire le schisme ? Ecclésiologies et politiques de I'Union entre Orient et Occident (xIII -xvIII' siècles) », Revue de I'histoire des religions [En ligne], 3 | 2015, mis en ligne le 21 octobre 2015, consulté le 25 septembre 2020. URL : http:// journals.openedition.org/rhr/8436; DOI : https://doi.org/10.4000/rhr.8436

Ce document a été généré automatiquement le 25 septembre 2020

Tous droits réservés 


\section{Marie-Hélène BLANCHET, Frédéric GABRIEL (éd.), Réduire le schisme? Ecclésiologies et politiques de l'Union entre Orient et Occident (XIII ${ }^{e}-\mathrm{XVIII}{ }^{e}$ siècles)}

Paris, Collège de France - CNRS/Centre de recherche d'histoire et civilisation de Byzance (« Monographies », 39), 2013

\section{Camille Rouxpetel}

\section{RÉFÉRENCE}

Marie-Hélène BLANCHET, Frédéric GABRIEL (éd.), Réduire le schisme ? Ecclésiologies et politiques de l'Union entre Orient et Occident (XIII $-\mathrm{XVIII}{ }^{e}$ siècles), Paris, Collège de France CNRS/Centre de recherche d'histoire et civilisation de Byzance (« Monographies », 39), 2013, 24 cm, 377 p., $30 €$, ISBN 978-2-916716-40-4.

1 En regroupant les contributions de 17 médiévistes et modernistes, orientalistes et occidentalisants, les éditeurs scientifiques envisagent le schisme comme une clef de lecture des relations inter et intracommunautaires «qui permet de relier et de comparer des espaces et des périodes » (p. 1). Bien que portant surtout sur l'Occident latin et l'Orient grec, l'étude de la question de l'Union des Églises transcende ainsi les frontières disciplinaires, temporelles et territoriales.

2 L'ecclésiologie, en articulant l'individu et la communauté, suppose une approche débordant la seule théorie religieuse pour accorder une attention renouvelée aux territoires et à la sphère civile, notamment aux enjeux de pouvoir qui la sous-tendent. L'enquête ne prétend certes pas à l'exhaustivité. Menée sur le temps long et à partir 
d'objets singuliers, elle implique de prendre en compte les rythmes de l'évolution diachronique et la diversité synchronique des ecclésiologies et des politiques de l'Union entre Orient et Occident du XIII ${ }^{\mathrm{e}}$ au XVIII ${ }^{\mathrm{e}}$ siècle. Cette exigence se fonde sur une étude précise de la terminologie (E. Morini et N. Papaïliaki) et une critique non moins précise des sources (L. Silvano et C. Gastberger). L'analyse des conditions et des lieux de leur production et de leur diffusion permet en outre une meilleure compréhension des enjeux religieux et politiques de la polémique (A. Rigo, M. Scarpa et F. Gabriel). La difficulté d'une définition historique du schisme conduit ainsi à réfléchir aux conditions mêmes de son apparition, notamment dans le cadre de la dynamique unioniste (M.-H. Blanchet, p. 7). Dominée par les initiatives romaines, elle conduit ses artisans à définir et à affirmer une identité de la chrétienté centrée sur Rome, réduisant donc le tout, la chrétienté, à une partie, Rome, qui prétend à l'universalité. Ainsi, plus qu'elle n'y met un terme, l'Union révèle la profondeur du schisme (M.-H. Blanchet, p. 10).

3 L'ouvrage est divisé en trois parties, mêlant périodes et points de vue: Contextes polémiques et tentatives conciliaires; Élaborations doctrinales et contestations de l'Union; L'Union en question aux frontières. Quatre thèmes affleurent: les usages polémiques de l'histoire ; les sources de la connaissance de l'Autre, entre culture savante et rencontre de visu; le schisme et l'Union comme révélateurs des fronts externes comme des fronts internes ; l'articulation entre doctrine et expérience, des conciles aux situations locales.

4 À l'élucidation des causes du schisme, destinée à reporter la faute sur l'Autre (voir du point de vue byzantin les contributions de L. Silvano, M. Stavrou, M.-H. Congourdeau et Ch. Triantafyllopoulos), le traité du patriarche de Jérusalem, Nektarios, et sa publication en latin à Londres en 1702 par le huguenot français Pierre Allix, ajoute un autre usage de l'histoire, devenue quête des origines. Allix, présentant les Grecs comme des frères, fonde son combat contre l'Église romaine sur l'antiquité de l'ecclésiologie orientale (F. Gabriel, p. 197-236). Cette stratégie de légitimation n'implique pas pour autant un savoir exclusivement conciliaire ou patristique. Elle s'ancre aussi dans une connaissance des arguments polémiques utilisés par les contemporains du parti adverse.

5 L'historiographie humaniste a construit le topos de l'ignorance médiévale du grec, ignorance nuancée par divers travaux dans lesquels s'inscrivent plusieurs contributions, portant certes souvent sur des contacts frontaliers entre Grecs et Latins (voir l'identification par C. Gastberger des citations utilisées dans une collection de textes favorable à l'Union émanant du clergé de Corfou dans la seconde moitié du XIV ${ }^{\mathrm{e}}$ s., p. 246-255). Le choix de privilégier des objets divers et circonscrits permet une étude en situation des enjeux des sources de la connaissance de l'Autre et évite l'écueil de la simple identification des citations et des sources, ou encore l'énoncé de considérations générales sur l'entreprise de traduction de textes grecs et latins. Les contributions de M. Stavrou, de C. Delacroix-Besnier, de M.-H. Congourdeau et de S. Kolditz permettent en outre de battre en brèche l'idée d'un argumentaire polémique figé, fondé sur les seules connaissances patristiques. Ainsi, les rencontres théologiques constituent autant d'occasions d'approfondir la connaissance de l'Autre (voir dans la contribution de M. Stavrou le récit des contacts noués à Nymphée en 1250, p. 53-54). L'étude de l'œuvre polémique des frères prêcheurs de Péra entre les $\mathrm{XIII}^{\mathrm{e}}$ et $\mathrm{xv}^{\mathrm{e}}$ siècles montre une multiplication et une diversification des sources utilisées et citées par les missionnaires dominicains. Deux opuscules de Nil Cabasilas, archevêque de Thessalonique et 
théologien $\mathrm{du} \mathrm{XIV}^{\mathrm{e}}$ siècle, constituent d'autres indices de la connaissance de l'argumentation adverse. Aux sources savantes et documentaires s'ajoute l'accroissement des contacts épistolaires et directs, attestés pour les Prêcheurs de Péra évoquant les Groeci moderni (C. Delacroix-Besnier, p. 57-68) et supputés dans le cas du théologien grec (M.-H. Congourdeau, p. 79). Enfin, l'étude des deux commentaires par Ioannès Eugénikos et Juan de Torquemada du décret florentin de l'Union des Églises rend manifeste l'influence de l'expérience conciliaire vécue sur la démarche du théologien byzantin (S. Kolditz, p. 83-100). Certes l'érudition et l'argumentation voisinent souvent avec la polémique et il s'agit essentiellement de répondre à des enjeux diplomatiques et missionnaires, et non pas de développer une meilleure connaissance en soi des Églises grecque et latine.

6 Ces différents exemples témoignent néanmoins d'interactions permanentes entre théologiens grecs et latins dans des contextes variés, et mettent également en lumière les enjeux de la réception des ecclésiologies et des politiques de l'Union au sein des sociétés concernées. Ainsi, durant la première moitié du xive siècle, les dominicains de Péra distinguent l'attitude des lettrés (intelligentes), perméables à leurs arguments, et celle du peuple (populares), plus réticent, voire hostile. Peut-être faut-il voir dans ces remarques, fréquentes dans la littérature polémique présentant les hérétiques comme des êtres dépourvus de raison ou dans les récits d'autres missionnaires dominicains (le Toscan Riccoldo da Monte Croce à propos des nestoriens rencontrés à Bagdad à la fin $\mathrm{du}$ XIII ${ }^{\mathrm{e}}$ siècle), une volonté de légitimer leur position autant qu'un reflet de l'accueil effectivement reçu par les Prêcheurs ? Les deux conciles d'Union de Lyon II (1274) et de Ferrare-Florence (1438/39) révèlent les divisions internes à la société et au clergé byzantin. E. Morini s'attarde sur la définition du terme "unionistes ", insistant sur la diversité des situations qu'il désigne, selon les périodes et selon les contextes (p. 13-16). Le refus d'une partie des orthodoxes de l'ecclésiologie, toute romaine, du décret florentin, venant contredire la théorie de la pentarchie, mène à la formation d'une Église parallèle, la "Synaxe des orthodoxes ", épousant l'ambition d'un front antiromain élargi à tous les chrétiens qui refusent l'obédience romaine, en commençant par les hussites (M.-H. Blanchet, p. 181-196). Enfin, la figure du patriarche d'Antioche Macaire III Ibn al-Za'îm (1647-1672) reflète les hésitations du clergé syrien entre mondes catholique et orthodoxe aux XVI ${ }^{\mathrm{e}}$-XVII ${ }^{\mathrm{e}}$ siècles (V. Tchentsova, p. 313-335).

7 L'exemple de l'Union de Brest (1595-1596) déplace «le face-à-face entre "Grecs" et "Latins" vers la polémique entre Ruthènes uniates et orthodoxes de Pologne-Lituanie " et présente un projet d'Union «fondé sur un ensemble de conditions concrètes [...] n'abordant que sommairement les désaccords théologiques" (L. Tatarenko, p. 102). Le changement d'échelles et l'analyse des politiques de l'Union, du modèle universel créé par le concile - spécialement celui de Ferrare-Florence - à des situations locales et singulières, conduit ainsi à s'interroger sur l'articulation entre doctrine et expérience, entre démarche dogmatique et approche plus pragmatique, à la suite de contributions de L. Tatarenko, de K. Vetochnikov ou d'A. Girard, ce dernier mettant en évidence la négociation comme l'une des méthodes définies par Rome pour parvenir à l'Union (p. 337-352). L'analyse par D. I. Mureşan du patriarcat latin de Constantinople et des difficultés de concilier les ecclésiologies grecque et romaine, permet enfin d'aborder la question de l'Union sous l'angle du déplacement des enjeux ecclésiologiques du niveau théorique au niveau politique et juridictionnel (p. 277-302). 
8 En faisant de l'ecclésiologie « un observatoire privilégié et fortement cohérent de la chrétienté " (p.1), cet ouvrage résonne comme une invitation à poursuivre collectivement ce nouveau chantier historiographique, invitation à laquelle tout chercheur s'intéressant à une histoire de la chrétienté transcendant les rives de la Méditerranée ne peut guère résister.

\section{AUTEURS}

CAMILLE ROUXPETEL

École française de Rome. 